\title{
The Assessment of Some Serum Biomarkers of Fibromyalgia Syndrome in Pre and Postmenopausal Women in Relation to Obesity Eman S. Saleh ${ }^{*}$, \\ * Department of Clinical Laboratory Science, College of Pharmacy, University of Baghdad, Baghdad, Iraq
}

\section{Abstract}

The objective of this study is to evaluate the level of parathyroid hormone (PTH), Co enzyme Q (Co Q) and total antioxidant status (TAS) in serum's women with fibromyalgia syndrome firstly, then to assess the influence of age and obesity on these biomarkers.

This study was performed at Rheumatology and Rehabilitation Consultation Unit in Baghdad Teaching Hospital. Blood sampling from (59) women with fibromyalgia syndrome (FMS) and (30) control be taken. The mean age of FMS group was $(42.22 \pm 15.34)$ years and for control was $(40.7 \pm 18.22$ years) and body mass index (BMI) for patients and control were $(31.83 \pm 5.05$ and 30.09 \pm 4.87$)$ correspondingly. Those participants were subdivided into four different groups according to menopausal status; FMS before menopause were $(30.14 \pm 10.58$ and for control were $29.74 \pm 12.21)$ years, post menopause FMS age were $(53.2 \pm 16.18$ and control were 47.8 \pm 12.51 ) years and BMI to measure serum (PTH and Co Q) by enzyme linked immune sorbent assay (ELISA) and (TAS) by spectrophotometry. Results analyzed by SPSS version 24, independent samples T-test and Pearson's correlation, $\mathrm{P}$ values $<0.05$ were considered significant.

The results record increment of serum's PTH levels significantly, decrement of Co Q (P value $<0.05)$ and non- significant decreased TAS (P value $>0.05)$ in FMS comparing with control group. Considering the age; PTH serum level showed insignificant increase and decrease of (Co Q \& TAS) (P value $>0.05 \& \mathrm{P}$ value $<0.05$ ) respectively in post menopause comparing with pre menopause. According to BMI; serum PTH level record a significant raise in obese group ( $\mathrm{P}$ value $<0.003$ ), reduction of serum Co Q significantly (P value $<0.05)$ and insignificantly for TAS ( $\mathrm{P}$ value> 0.05).

The mean serum level of PTH before menopause correlate significantly with TAS $(\mathrm{P}$ value $=0.034)$ also with Co $\mathrm{Q}$ of both FMS and control groups when $\mathrm{BMI}>30(\mathrm{P}$ value $=0.029$ and $\mathrm{P}$ value $=0.043)$ respectively. In post menopause of both (FMS and control) PTH correlate positively ( $\mathrm{P}$ value=0.05).

Independent T- test for pre and post menopause FMS showed significance variance in TAS only $(\mathrm{P}$ value $=0.004)$. Independent T- test for obese and non- obese FMS showed significant variance in PTH and TAS (P value= 0.032 and $\mathrm{P}$ value $=0.0001$ ).

In conclusion the obesity and menopause play an imperative role in the etiology of FMS relative with serum's biomarkers (PTH, Co Q and TAS).

Keywords: Obesity, Menopause, Fibromyalgia syndrome, Parathyroid hormone, Total anti- oxidant status, Co enzyme $Q$.

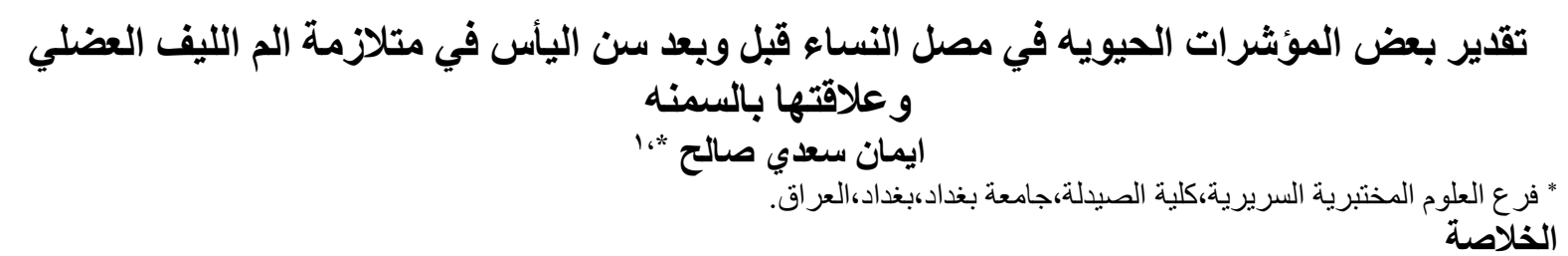

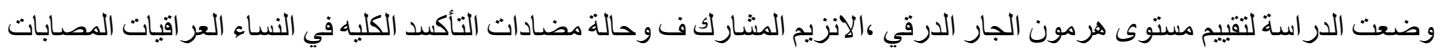

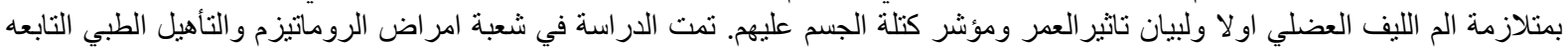

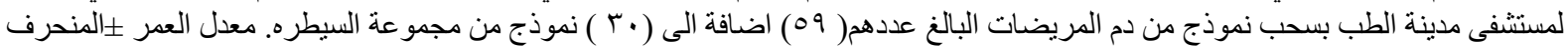

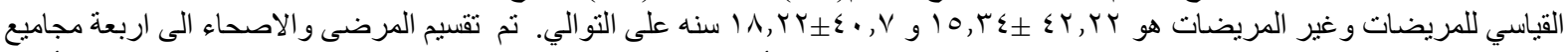

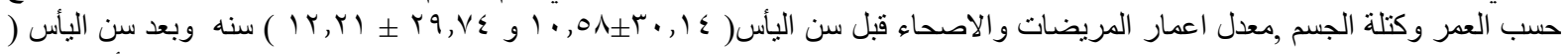

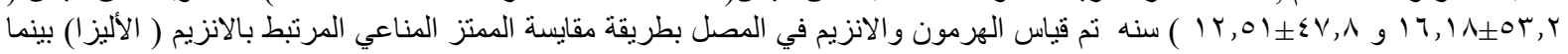
مقايسة مضادات الاكسده بطريقة التعيين اللوني.

${ }^{1}$ Corresponding author E-mail:dr.emansaadi@yahoo.com Received: 10/ 3 /2019 Accepted: 11/5 / 2019

Iraqi Journal of Pharmaceutical Sciences 


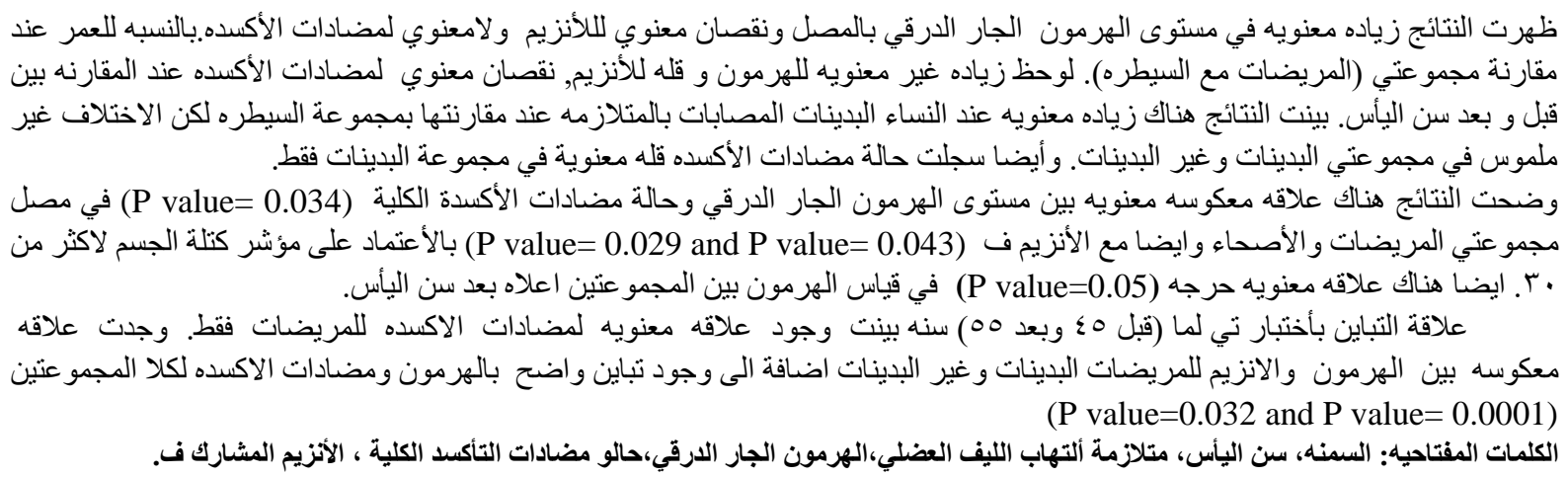

\section{Introduction}

Fibromyalgia syndrome (FMS) is a chronic disorder which has been defined by a history of widespread pain and the presence of marked tenderness to palpation at standard anatomicallydefined tender points ${ }^{(1)}$. Fibromyalgia (FM) was recognized as a true syndrome with the publication of the American College of Rheumatology (ACR) classification criteria in 1990, which were updated in $2010^{(1,2)}$.

The parathyroid glands maintain the serum levels of calcium $(\mathrm{Ca})$ and phosphorus $(\mathrm{P})$. Calcium plays a dynamic role in metabolic processes ${ }^{(3)}$. There is a large symptom overlap between hyperparathyroidism (HP) and FM so the subjects experience "fatigue, musculoskeletal pain, headache, cognitive dysfunction, and mood disturbance" (4).

Coenzyme Q ( Co Q ) or $\mathrm{Q}_{10}$ is a small fat-soluble, vitamin-like substance located in mitochondria that transfers reducing equivalents from complexes I and II to complex III of the respiratory chain. Some chronic disease conditions are also thought to either reduce the biosynthesis and/or increase the demand for Co Q in the body, but there are no definite data to support these claims ${ }^{(5,6)}$.

Reactive oxygen species (ROS) is produced in metabolic and physiological processes. Under certain conditions, the increase in oxidants or decreased in antioxidants that cannot be prevented, and the disorders related to oxidative stress would develop. Antioxidant molecules prevent or inhibit these harmful reactions. The antioxidant system consist of enzyme and non- enzyme anti-oxidants. Antioxidants prevent free radical induced tissue damage by preventing the formation of radicals, scavenging them, or by promoting their decomposition ${ }^{(7-9)}$. The definition of TAS is the sum total of endogenous and food derived antioxidants of the extra cellular fluid of an individual ${ }^{(10)}$.

\section{Aim of study}

To estimate serum biochemical markers \{parathyroid hormone (PTH), Co Q and total antioxidant status (TAS) $\}$ in women with FMS and evaluate the effect of age and obesity on these biomarkers.

\section{Subjects, materials and methods}

The work was started in September/ 2014 to January/ 2015 at Baghdad Teaching Hospital / Rheumatology and Rehabilitation Consultation Unit, by the assortment of women with FMS which was accomplished under observation of rheumatologist according to American College of Rheumatology (ACR) criteria (11). In this study, blood sample were withdrawn from (59) females with FMS and (30) control subjects without FMS in order to obtain the serum after centrifugation of the clotted specimens. All applicants were classified consistent with their menopausal status before 45 years refer to pre menopause and after 55 years be in post menopause as shown in (figure 1). Note: Each subject must follow above condition. The mean age of FMS before menopause were $(30.14 \pm 10.58$, control were $29.74 \pm 12.21)$ years; the post menopause FMS were $(53.2 \pm 16.18$ and control were $47.8 \pm 12.51$ ) years. Determination of (BMI) was by dividing body weight in kilograms over the height in meters square $\{\mathrm{BMI}=$ Weight (kg) / Height $\left.\left(\mathrm{m}^{2}\right)\right\}^{(12)}$ (figure 2).

The assessment of serum PTH (Demeditec Diagnostics $\mathrm{GmbH} / \mathrm{Germany)}$ and Co enzyme Q (Cusabio Biotech Co., Ltd, /China) were done by enzyme linked immune sorbent assay (ELISA); this assay employs the competitive inhibition enzyme immunoassay technique. The colorimetric method Randox kit used to assess total antioxidant status (TAS) ${ }^{(13-15)}$. Inclusion and exclusion criteria for subjects selected to participate in the study was shown in table 1 . 
Table 1. the selection criteria for FMS and control women

\begin{tabular}{|c|c|}
\hline Inclusion criteria & Exclusion criteria \\
\hline $\begin{array}{l}\text { The age range of subjects } \\
20-60 \text { years. The mean age } \\
\text { (M) } \pm \text { standard deviation of } \\
\text { mean (SD) of the patients } \\
\text { was }(42.22 \pm 15.34) \text { years } \\
\text { and the control group was } \\
(40.7 \pm 18.22) \text { years as well } \\
\text { as complete blood picture } \\
\text { and erythrocyte } \\
\text { sedimentation rate (ESR) } \\
\text { tests were within normal } \\
\text { range }\end{array}$ & $\begin{array}{l}\text { All women had any } \\
\text { endocrinopathiy, } \\
\text { autoimmune, } \\
\text { inflammatory, } \\
\text { rheumatologic disorders, } \\
\text { chronic and systemic } \\
\text { disease in addition the } \\
\text { pregnant and lactating } \\
\text { subjects. }\end{array}$ \\
\hline
\end{tabular}

Figure 1 refers to distribution of subjects shared this work classified according to their ages less than 45 years as pre- menopause and more than 55 years as post menopause while figure 2 expressed the classification of both FMS\& control along with their BMI as normal BMI if less than 25 and obese BMI more than 30 .

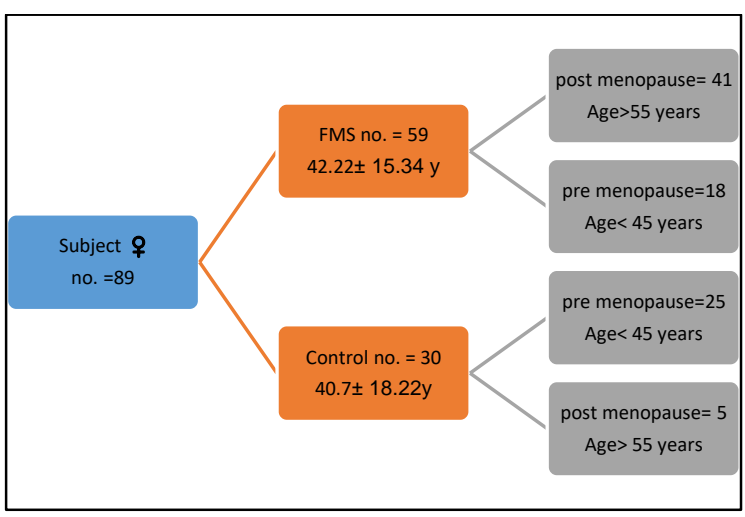

Figure1. Demographic distribution of volunteers (FMS and control) according to age in this study

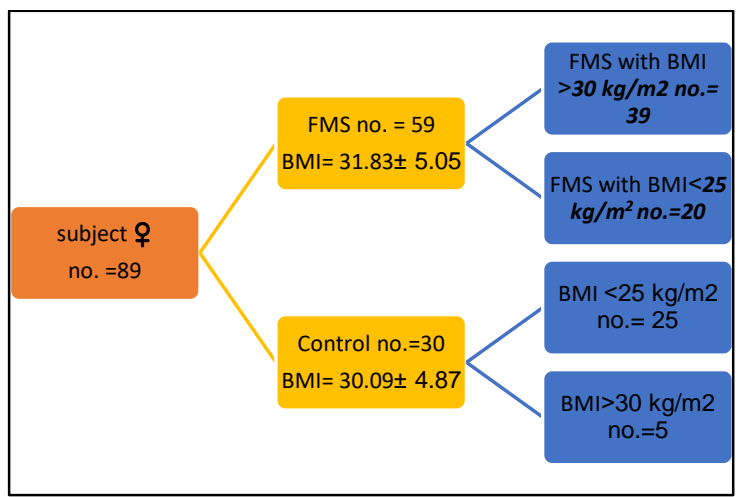

Figure2.Demographic distribution of (FMS and control) women according to BMI in this study.

The statistical analysis was done by using SPSS (version 24) for values of measurement of serum biomarkers levels which expressed as mean \pm SD. Also independent T-test sample were used to complete the analysis and Pearson's correlation between studied biomarkers in different groups. $\mathrm{P}$ value is significant $<0.05$.

\section{The results}

This trial showed a significantly ( $\mathrm{P}$ value $<$ 0.01) increased serum level of PTH in FMS when compared with control, while the significant decrease of Co Q (P value < 0.01) and insignificant ( $\mathrm{P}$ value $>0.01$ ) decline in TAS for all subjects as shown in (figures 3,4 and 5, respectively). The mean age \pm SD of both FMS and control were $(42.22 \pm 15.34)$ and $(40.7 \pm 18.22)$ years and BMI were $(31.83 \pm 5.05)$ and $(30.09 \pm 4.87) \quad \mathrm{kg} / \mathrm{m} 2$ respectively.

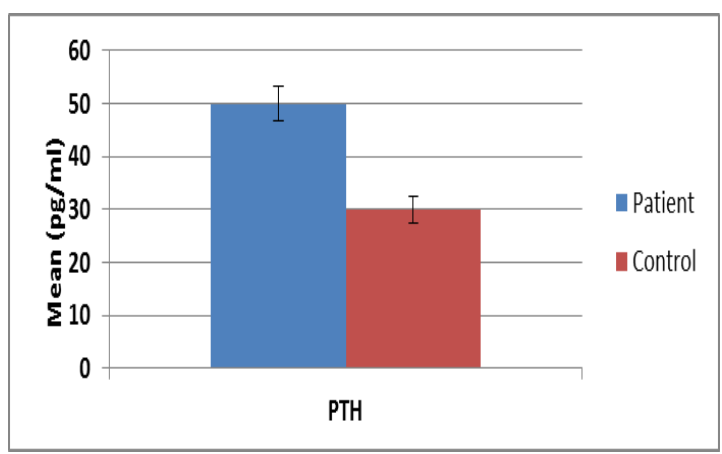

Figure 3. The mean serum PTH level $(\mathrm{pg} / \mathrm{ml})$ in FMS and control groups $(P$ value $<0.01)$

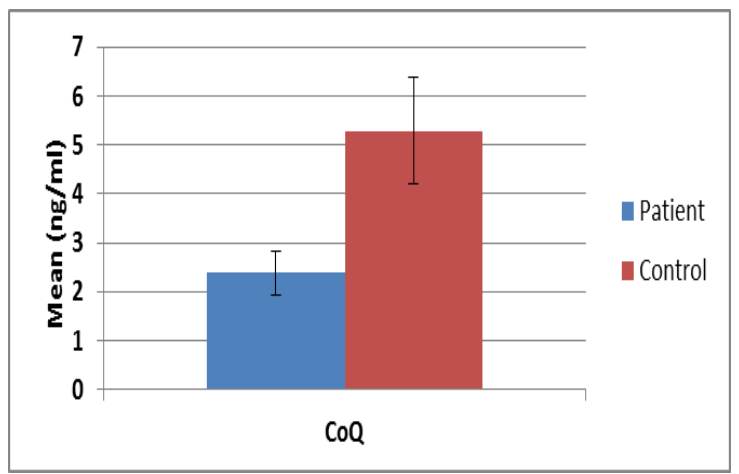

Figure 4. The mean serum Co $Q$ level $(\mathrm{ng} / \mathrm{ml})$ in FMS and control $(P$ value $<0.01)$

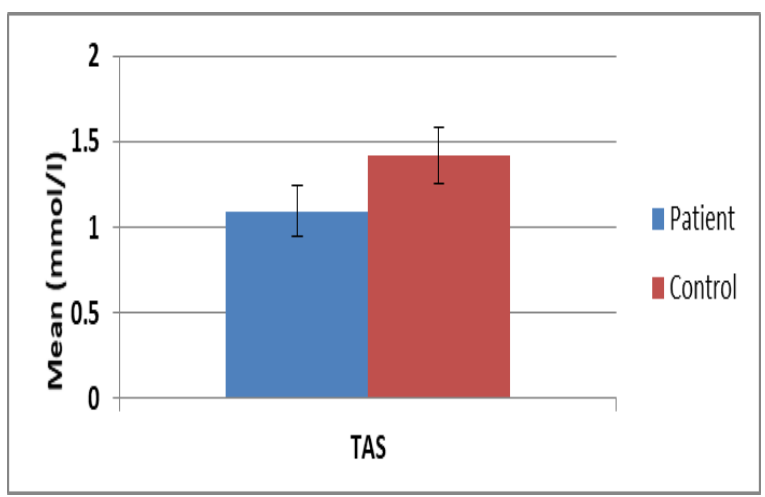

Figure 5.The mean serum TAS level (mmol/l) in both FMS and control groups ( $P$ value $>0.05$ ) 
Above groups were discrete into four subdivisions. The first two groups demonstrate the levels of serum biomarkers in FMS and control as post menopause while reminder two groups in pre menopause, these information are listed in table 2. The significant increasing of serum level of PTH in both age groups with FMS (P value< 0.005), significant decreasing of serum Co Q level (P value $<$ 0.005 ) and significant decrease in TAS in post menopause group but insignificant in pre menopause groups when compared with control ( $\mathrm{P}$ value $<0.05$ and $\mathrm{P}$ value $>0.01$ respectively)

Table 2. The serum level of biochemical markers in both FMS patients and control distributed according to their ages represented by (mean \pm SD).

\begin{tabular}{|c|c|c|c|c|c|c|}
\hline \multicolumn{7}{|c|}{ age $>55$ years } \\
\hline & \multicolumn{3}{|c|}{ FMS patient no. $=41$} & \multicolumn{3}{|c|}{ Control no. $=5$} \\
\hline Serum & PTH: pg/ml & CoQ: ng/ml & TAS: $\mathrm{mmol} / \mathrm{l}$ & PTH:pg/ml & CoQ:ng/ml & TAS:mmol/l \\
\hline $\begin{array}{l}\text { mean } \pm \\
\text { SD }\end{array}$ & $52.15 \pm 16.26^{* *}$ & $2.36 \pm 0.68 * *$ & $1.025 \pm 0.06^{*}$ & $30.20 \pm 12.51$ & $5.51 \pm 2.07$ & $1.39 \pm 0.15$ \\
\hline \multicolumn{7}{|c|}{ age $<45$ years } \\
\hline & \multicolumn{3}{|c|}{ FMS patient no. $=18$} & \multicolumn{3}{|c|}{ Control no. $=25$} \\
\hline Serum & PTH:pg/ml & CoQ:ng/ml & TAS:mmol/l & PTH:pg/ml & CoQ:ng/ml & TAS:mmol/1 \\
\hline $\begin{array}{l}\text { mean } \pm \\
\text { SD }\end{array}$ & $49.07 \pm 24.29 * *$ & $2.38 \pm 0.72 * *$ & $1.12 \pm 0.16$ & $29.74 \pm 14.21$ & $5.24 \pm 2.63$ & $1.43 \pm 0.2$ \\
\hline
\end{tabular}

Table 3 shows the effect of obesity on serum biomarkers levels in normal and obese (FMS and control) groups. The results appear that the value of PTH in serum was increased significantly and highly significant $(\mathrm{P}$ value $<0.01, \mathrm{P}$ value $<0.005)$ in both normal and obese respectively when compared with control groups. The serum level of Co Q shows high significant decreasing in normal and obese FMS groups, insignificant decreased for TAS in comparison with control group $(\mathrm{P}$ value $<0.005 \& \mathrm{P}$ value $>0.05)$.

Table 3.The serum level of biochemical markers (mean \pm SD) in FMS and control distributed according to their BMI.

\begin{tabular}{|c|c|c|c|c|c|c|}
\hline & \multicolumn{6}{|c|}{ BMI $<25$} \\
\hline & \multicolumn{3}{|c|}{ FMS patient no. $=20$} & \multicolumn{3}{|c|}{ Control no. $=25$} \\
\hline serum & PTH:pg/ml & CoQ:ng/ml & TAS:mmol/l & PTH:pg/ml & CoQ:ng/ml & TAS:mmol/l \\
\hline \multirow[t]{3}{*}{$\begin{array}{l}\text { mean } \pm \\
\text { SD }\end{array}$} & $35.42 \pm 12.04 *$ & $2.20 \pm 0.85 * *$ & $1.36 \pm 0.1$ & $27.80 \pm 12.89$ & $4.12 \pm 0.4$ & $1.72 \pm 0.13$ \\
\hline & \multicolumn{6}{|c|}{$\mathrm{BMI}>30$} \\
\hline & \multicolumn{3}{|c|}{ FMS patient no. $=39$} & \multicolumn{3}{|c|}{ Control no. $=5$} \\
\hline Serum & PTH:pg/ml & CoQ:ng/ml & TAS:mmol/l & PTH:pg/ml & CoQ:ng/ml & TAS:mmol/l \\
\hline $\begin{array}{l}\text { mean } \pm \\
\text { SD }\end{array}$ & $52.57 \pm 22.65^{* *}$ & $2.4 \pm 0.68 * *$ & $1.04 \pm 0.09$ & $30.22 \pm 14.11$ & $5.51 \pm 2.7$ & $1.35 \pm 0.14$ \\
\hline
\end{tabular}

The mean serum level of PTH before menopause correlate significantly with TAS $(\mathrm{P}$ value $=0.034)$ also with Co Q of both FMS and control groups when $\mathrm{BMI}>30(\mathrm{P}$ value $=0.029$ and $\mathrm{P}$ value $=0.043)$ respectively. In post menopause of both (FMS and control) PTH correlate positively ( $\mathrm{P}$ value $=0.05$ ). Independent $\mathrm{T}$ - test for pre and post menopause FMS showed significance variance in TAS only ( $P$ value $=0.004)$. Independent $\mathrm{T}$ - test for obese and non- obese FMS showed significant variance in PTH and TAS $(\mathrm{P}$ value $=0.032$ and $\mathrm{P}$ value $=0.0001)$.

\section{Discussion}

Fibromyalgia syndrome (FMS) is classified as a first-order syndrome or a symptom complex with unknown or unclear etiology, heterogeneous pathogenesis and a defined phenotype; second - order syndromes (sequences) are defined by unknown etiologies, homogeneous pathogenesis and defined phenotypes; Third-order syndromes are defined by homogeneous etiologies, unknown or insignificant pathogenesis and defined phenotypes types ${ }^{(16)}$. 
The results show hyperparathyroidism of FMS group if comparing with control so it is in concomitant with the result of Armagan et al (17) measured serum PTH, calcium, phosphorus and active vitamin D showing in significant increase of PTH. Another study done by Shaheen et al through approved the deficiency of vitamin $\mathrm{D}$ in fibromyalgia ${ }^{(18)}$. Ferrari R et al studied the rate of prevalence related with primary hyperparathyroidism in widespread and localized musculoskeletal pain were $6.4,5.5$, and $6.1 \%$, respectively (19). Previous studies $(20,21)$ show FMS have a predisposition to osteopenia. Measurement Co Q, in this study showed deceasing in serum level of FMS so this clarify the mitochondrial dysfunction of muscle \& neural cell which is a part of electron transport chain (ETC), affect the synthesis of ATP pools and finally lead to widespread pain ${ }^{(22)}$. Study on osteoarthritis demonstrated the same results ${ }^{(23)}$. In US ${ }^{(24)}$; Co Q supplements were set as foods not as drug. About TAS and oxidative stress: this study illustrate that the level of TAS was decreased insignificantly because of presence of reactive oxygen species (ROS) in excess result in cell damage and lipid peroxidation ${ }^{(25)}$. Chung et al study match with current study in relation with oxidative stress and FMS ${ }^{(26)}$.Turkish authors compare between FMS\& obstructive sleep apnea syndrome in assessing anti-oxidant enzymes (catalase, superoxide dismutase and glutathione peroxidase) were significantly lowered at the same time malondialdehyde was increased so this finding like the present study's result (27). The role of oxidants/antioxidants, mitochondrial dysfunction, and autophagy in fibromyalgia was published recently ${ }^{(28)}$.

The effect of age on serum biochemical markers showed that the variation between pre and postmenopausal groups were unclear insignificant but when compare with control group demonstrate significant differences this finding belongs PTH similar to recent study done by Guncha K and Gagan $\mathrm{D}$ that showed significant correlation of age with serum PTH in both pre-menopausal and postmenopausal women ${ }^{(29)}$ because an impairment of ovarian function in postmenopausal women alter the metabolism of $\mathrm{Ca}$ and therefore reduce bone mass (30). Borgia et al. demonstrate the role of hyperparathyroidism in musculoskeletal pain of fibromyalgia ${ }^{(31)}$. In correspondence of present study with Cammozi et al and Safi et al observations that parathyroid hormone was significantly low in postmenopausal women ${ }^{(32,33)}$. Eastell et al and Khosla et al in different studies described the progress of age lead to increase turnover of bone due to raise the blood level of parathyroid hormone and lower estrogen $(34,35)$. The role of estrogen in inhibiting interleukin six was decreased with age so lead to prolongation of osteoclast's life span (36). Sainaghi et al demonstrated the relation between low levels of vitamin D in different rheumatic diseases with higher production of PTH ${ }^{(37)}$. Recent Turkish study bone mass and bone turnover measurement for premenopausal women with FMS and degenerative disc disease control patients; the authors demonstrated that presence of depression, general pain and other clinical findings in FMS created women to be susceptible to osteoporosis ${ }^{(38)}$.

Oxidative stress (OS) and Co Q play a role in neuro- musculoskeletal conditions such as FM so the providing of antioxidants kept tissues faraway from unpleasant effects of OS ${ }^{(39-42)}$. In Egyptian study by Soliman et al showed that the level of (OS) increased with decreased of antioxidant capacity significantly these findings in concomitant with the present study in premenopausal age ${ }^{(43)}$. Another Spanish study determined total anti-oxidant capacity in 82 postmenopausal FM women and compared with 25 apparent healthy as control their results showed significantly decreased TAS when compared with controls( Zinc, Uric acid, Ferritin, iron, Catalase, SOD, GPx ) as a result of enhancement of OS in FM because of elevation of protein peroxidation and oxidative DNA damage significantly and generated advanced glycation endproducts (AGEs) so this modified proteins became more resist to be digest, as well as excite cytokines, adhesion molecules, and growth factors expression through NF- $\kappa B$ stimulant ${ }^{(44)}$. Niklowitz et al mentioned the blood level of Co Q was decreased in old German people so the redox status be shift to oxidized direction ${ }^{(45)}$.

The impact of obesity on current FMS study and comparison between obese and nonobese, looked through elevation of PTH increased significantly at the same time decreased of TAS serum level. This syndrome is one of musculoskeletal disorder with obesity agree with old study by Christensen et al in their demonstrating the combination of obesity with certain rheumatologic conditions specifically knee osteoarthritis ${ }^{(46)}$. Other studies showed the effects of obesity on clinical examination of FMS by measuring tenderness, symptoms, quality of life ${ }^{(47,48)}$. Okifuji et al assessed catecholamines, cortisol, C-reactive protein and interleukin- 6 as neuroendocrine indices as well as measuring some clinical manifestation such as symptoms, treadmill testing and indices of sleep in thirty eight FMS patients ${ }^{(49)}$. There are different mechanism to explain the association of fibromyalgia and obesity in accordance to endocrine dysfunction; one of them is impairment of growth hormone and insulin growth factor-1 (IGF-1) secretion this finding illustrated in FM patients by Bennett et al. and in obese subjects by Maccario et $a l .^{(50-52)}$. Authors in 2008 published their results that demonstrate bone mineral density and serum level of osteocalcin and IGF-1 which decreased significantly and insignificant decrease calcium, phosphorus, vitamin D3 and PTH in premenopausal 
FMS with mean BMI $25.63 \pm 3.14 \mathrm{~kg} / \mathrm{m} 2{ }^{(16)}$. In Spain; Aparicio et al. observed the effect of obesity and over weight on pain, fatigue, stiffness and physical functioning and play a role in progress of these FM symptoms ${ }^{(53)}$. The association between pain of FM and obesity showed in old study due to central sensitization ${ }^{(54,55)}$. Kim et al mentioned that the greater BMI had greater fibromyalgia-related symptoms through their study on wide range of BMI by classify the patients into four groups (non- obese, overweight, moderately obese and severely obese) (56). Jameel M. G. et al demonstrated the effect of obesity on serum total calcium, myeloperoxidase and vitamin D3 in Iraqi FMS patients in addition to fetuin $-\mathrm{A}$ and thyroid function test in two different publishing studies ${ }^{(57,58)}$. In the longitudinal analyses demonstrate an association between weight loss of obese middle-aged patients with localized weightbearing joints pain by studying $\mathrm{C}$ reactive protein, interleukins, tumor necrosis factor- $\alpha$ and interferon$\gamma^{(59)}$. Brazilian authors studied the effect of overweight and obesity on serum levels of some adipokines in FM middle aged women ${ }^{(60)}$. Turkish study include 124 FMS women classified into normal BMI, overweight and obese to assess pain, tender point count, disease activity, anxiety and depression in ages between 18 - 55 years ${ }^{(61)}$. Cross sectional study in Turkey was done to evaluate the effects of obesity and over weight on FMS severity in relation to general health and psychological status (62)

Conclusion: The study clarify the influence of progressing age in general but chiefly after menopausal age when compared with age less than 45 years as well as obesity on serum level of PTH, Co $\mathrm{Q}$ and TAS in Iraqi FMS women through enhancing the oxidative stress and tissue damage as result directly or indirect accelerating pathophysiology, etiology and severity. Thus FMS women must recommended anti-oxidant supplements, vitamin D and minerals especially calcium, as well as advise them to improve lifestyle in order to decrease the undesirable effects of FMS.

\section{References}

1. Anil Kumar Jain, Bruce M. Carruthers: Fibromyalgia Syndrome: A Clinical Case Definition and Guidelines for Medical Practitioners An Overview of the Canadian Consensus Document. Journal of Musculoskeletal Pain; 2003, 11(4):3107.

2. Wolfe F, Clauw DJ, Fitzcharles MA et al: The American College of Rheumatology preliminary diagnostic criteria for fibromyalgia and measurement of symptom severity. Arthritis Care Res; 2010, 62, 5; 600-610.

3. Roseann P. Velez, Mary Donnelly-Strozzo, and Julie Stanik-Hutt: Simplifying the Complexity of Primary Hyperparathyroidism. The Journal for Nurse Practitioners - JNP; 2016, 12, 5.
4. Megan K. Applewhite, David F. Schneider: Mild primary hyperparathyroidism: a literature review. Oncologist, 2014;19: 919-929

5. Bozkurt M, Oktayoglu P, Em S, Mehmet C et al : Serum Coenzyme Q10 Levels and Oxidative Status in Patients with Fibromyalgia Syndrome Journal Of Musculoskeletal Pain, Early Online: 1-6, 2014 Informa Healthcare USA, Inc. ISSN: 1058-2452 print / 1540-7012 online DOI: 10.3109/10582452.2014.883040

6. Quinzii CM, Lopez LC, Naini A et al: Human CoQ10 deficiencies. Biofactors, 2008; 32: 113118.

7. Barry Halliwell and John M. C. Gutteridge: Free Radicals in Biology and Medicine Fifth Edition 2015 Oxford: Oxford Science Publication Chapter 10.

8. Young, I.S. and Woodside, J.V.: Antioxidants in Health and Disease. Journal of Clinical Pathology, 2001; 54, 176-186.

9. Sánchez-Domínguez B, Bullón P, Román-Malo $\mathrm{L}$ et al: Oxidative stress, mitochondrial dysfunction and, inflammation common events in skin of patients with Fibromyalgia; Mitochondrion, 2015, MITOCH-00992; No of Pages 7

10. Miller,N, Rice-Evans, C, Davies, MJ, A novel method for measuring antioxidant capacity and its application to monitoring the antioxidant status in premature neonates. Clin Sci, 1993, 84, 407-412.

11. Koopman WJ., Boulware DW., Gustavo R. et al: Fibromyalgia in Clinical Primer of Rheumatology, $14^{\text {th }}$ edition ,Lippincott Williams and Wilkins (editors) Philadelphia, 2003; 22635.

12. World Health Organization (WHO): Obesity and overweight .Fact sheet NO.311, 2008.

13. Marcus, R.: Laboratory diagnosis of primary hyperparathyroidism, Endocrinol Metab. Clin. North Am., 1989; 18:647-658.

14. Frances $\mathrm{T}$ Fischbach, Marshall $\mathrm{B}$ Dunning: Immunodiagnostic Studies in A Manual of Laboratory and Diagnostic Tests; ninth ed.; 2014, Chapter 8. Wolters Kluwer health / Lippincott Williams \& Wilkins.

15. Erel O. A novel automated direct measurement method for total antioxidant capacity using a new generation, more stable ABTS radical cation. Clin Biochem., 2004; 37(4):277-85.

16. Eich W, Häuser W, Arnold B et al: Fibromyalgia syndrome. Definition, classification, clinical diagnosis and prognosis, Der Schmerz, 2012; 3; 1-10. Published by Springer

17. Armağan O, Sırmagül $\varepsilon$, Ekim A et al : Levels of IGF-1 and Their Relationship with Bone Mineral Density in the Premenopausal Women with Fibromyalgia Syndrome; Rheumatism, 2008; 23: 118-23 
18. Shaheen A, Niaz A, Muhammad I et al: Vitamin D deficiency in Fibromyalgia. J Pak Med Assoc, 2010; 60 (11), 949-951.

19. Ferrari R\& Science A: Prevalence of primary hyperparathyroidism in a referred sample of fibromyalgia patients; Clinical Rheumatology. 2015; 34 (7), 1279-1283.

20.Zerahn B, Bliddal $\mathrm{H}$, Moller $\mathrm{P}$ et al.: Bone mass in the calcaneus in patients with fibromyalgia. $\mathrm{J}$ Musculoskeletal Pain, 2001; 9: 17-23.

21. Swezy RL\& Adams J.: Fibromyalgia: a risk factor for osteoporosis. J Rheumatol 1999; 26 : 2642-4.

22. Meeus M, Nijs J, Hermans L et al.: The role of mitochondrial dysfunctions due to oxidative and nitrosative stress in the chronic pain or chronic fatigue syndromes and fibromyalgia patients: peripheral and central mechanisms as therapeutic targets? Expert Opin Ther Targets. 2013; 17(9):1081-9.

23. Altındağ Ö, Koçyiğit A, Çelik N et al: DNA Damage and Oxidative Stress in Patients with Osteoarthritis: a Pilot Study; Rheumatism 2007; 22: 60-3.

24. National Cancer Institute (NCI). "PDQ® Coenzyme Q10". NCI, National Institutes of Health, US Dept. of Health and Human Services. "Thiamine, thiamine phosphates and their metabolizing enzymes in human brain" J Am Chem Soc. 2014; 80 (14): 37193726.

25. Halliwell B. Free radicals, antioxidants, and human disease: curiosity, cause, or consequence? Lancet. 1994; 344(8924):721-4.

26. Chung C, Titova D, Oeser A, et al: Oxidative Stress in Fibromyalgia and its Relationship to Symptoms: Clin Rheumatol. 2009; 28(4): 435438.

27. Yildirim $\mathrm{T}$ and ALP R: The role of oxidative stress in the relation between fibromyalgia and obstructive sleep apnea syndrome; European Review for Medical and Pharmacological Sciences: 2017; 21: 20-29

28. Alejandra M\& Simón R: The Role of Oxidants/Antioxidants, Mitochondrial Dysfunction, and Autophagy in Fibromyalgia; INTECH; 2018, Chapter 2, 13-33.

29. Guncha K and Gagan D: Serum Calcium, Parathyroid Hormones and Risk of Fracture in Premenopausal and Postmenopausal Women; Annals of International Medical and Dental Research, 2017; 3(5): OR24-OR27.

30. Garton M, Martin J, New S, et al: Bone mass and metabolism in women aged 45-55. Clin Endocrinal (Oxf). 1996; 44:563-73.

31. Borgia AR, Cavallasca JA, Costa CA et al.: Hyperparathyroidism: A Forgotten Cause of Musculoskeletal Pain; Rheumatol Clin. 2012; 8(5):298-301

32. Cammozi V, Lumachi $\mathrm{F}$, Mantero $\mathrm{F}$, et al: Phalangeal quantitative ultrasound technology and dual energy X-ray densitometry in patients with primary hyper parathyroidism: influence of sex and menopausal status. Osteoporosis International; 2003, 14 (7), 602-608

33. Safi S, Hassikou H, Messary A, et al: Severe primary hyperparathyroidism and vitamin D deficiency. Ann Endocrinol (Paris) 2004; 65(3):226-32

34. Eastell R, Yergey AL, Vieira $\mathrm{N}$, et al:: Interrelationship among vitamin $\mathrm{D}$ metabolism, true calcium absorption, parathyroid function and age in women: evidence of an age-related intestinal resistance to $1,25(\mathrm{OH})_{2} \mathrm{D}$ action. J Bone Miner Res 1991; 6:125-32.

35. Khosla S, Elizabeth J, Atkinson L, et al.: Effects of age and estrogen status on serum parathyroid hormone levels and biochemical markers of bone turnover in women: A population based study. $\mathbf{J}$ Clin Endocrinal Metabol. 1997; 82: 1522-7.

36. Garneo P\& Delmas PD. Bone turnover markers. In: Encyclopedia of Endocrine Diseases. Eds Martin L. California: Elsevier Inc; 2004.pp.40113.

37. Sainaghi PP, Bellan M, Antonini $G$ et al.: Unsuppressed parathyroid hormone in patients with autoimmune/inflammatory rheumatic diseases: implications for vitamin D supplementation. Rheumatology (Oxford). 2011 Dec; 50(12):2290-6.

38. Gurbuz A, Kaya A and Ansal T: Bone mass and bone turnover in premenopausal women with fibromyalgia syndrome; Medicine Science International Medical Journal; 2017, 06; 8669.

39. Miyamae T, Seki M, Naga T, et al.: Increased oxidative stress and coenzyme Q10 deficiency in juvenile fibromyalgia: amelioration of hypercholesterolemia and fatigue by ubiquinol10 supplementation. Redox Rep. 2013; 18: 12 19.

40. Fatima G, Das SK, Mahdi AA: Oxidative stress and anti-oxidative parameters and metal ion content in patients with fibromyalgia syndrome: implications in the pathogenesis of the disease. Clin Exp Rheumatol. 2013; 31: 128-133.

41. Cordero MD, Alcocer-Gómez E, de Miguel M, et al. Can coenzyme q10 improve clinical and molecular parameters in fibromyalgia? Antioxid Redox Signal. 2013; 19: 1356-61.

42. Pereira AP, Pereira LL, de Souza LC, et al: Involvement of Oxidative Stress and Nitric Oxide in Fibromyalgia Pathophysiology: A Relationship to be Elucidated. Fibrom Open Access 2016, 1:1

43. Soliman AF, El-Olemy GG, Hassan WA, et al: Impact of an intensive dynamic exercise program on oxidative stress and on the outcome in patients with fibromyalgia .Egyptian Rheumatology \& Rehabilitation 2016, 43 (3); 117-123 
44. Rubia M La, Rus A, Molina F, et al: Is fibromyalgia-related oxidative stress implicated in the decline of physical and mental health status? Clin Exp Rheumatol 2013; 31 (79): S121S127.

45. Niklowitz P, Onur S, Fischer A, et al: Coenzyme Q10 serum concentration and redox status in European adults: influence of age, sex, and lipoprotein concentration $\mathrm{J}$ Clin Biochem Nutr. 2016; 58(3): 240-245

46. Christensen R, Astrup A, Bliddal H: Weight loss: the treatment of choice for knee osteoarthritis? A randomized trial. Osteoarthritis Cart. 2005; 13:20-27.

47. Bennett RM, Jones J, Turk DC, et al: An internet survey of 2, 596 people with fibromyalgia. BMC Musculoskelet Disord. 2007; 8:27.

48. Neumann L, Lerner E, Glazer Y, et al: A crosssectional study of the relationship between body mass index and clinical characteristics, tenderness measures, quality of life, and physical functioning in fibromyalgia patients. Clin Rheumatol. 2008; 27(12): 1543-1547.

49. Okifuji A, Bradshaw DH, Olson C: Evaluating obesity in fibromyalgia: neuro endocrine biomarkers, symptoms, and functions. Clin Rheumatol. 2009; 28(4):475-478.

50. Bennett RM, Clark SR, Campbell SM et al: Low levels of somatomedin $\mathrm{C}$ in patients with the fibromyalgia syndrome. A possible link between sleep and muscle pain. Arthritis Rheum. 1992; 35(10):1113-1116.

51. Bennett RM, Cook DM, Clark SR et al: Hypothalamic-pituitary-insulin-like growth factor-I axis dysfunction in patients with fibromyalgia. J Rheumatol 1997; 24(7):13841389

52. Maccario M, Grottoli S, Procopio $M$ et al The GH/IGF-I axis in obesity: influence of neuroendocrine and metabolic factors. Int J Obes Relat Metab Disord. 2000; 24(S2):S96-S99

53. Virginia A. Aparicioa, Francisco B. Ortega, Ana Carbonell-Baezaa et al: Relationship of Weight Status with Mental and Physical Health in
Female Fibromyalgia Patients, Obes Facts. 2011; 4: 443-448

54. Okifuji A, Donaldson GW, Barck L et al: Relationship between fibromyalgia and obesity in pain, function, mood, and sleep. J Pain. 2010; 11(12):1329-1337.

55. Yvonne D'Arcy: Managing pain in obese patients; The Nurse Practitioner, 2011; 36 (12); 28-32

56. KIM CH, LUEDTKE CA, VINCENT A et al: Association of Body Mass Index With Symptom Severity and Quality of Life in Patients With Fibromyalgia; Arthritis Care \& Research, 2012; 64 (2), 222-228

57. Murooj G J, Eman S S, Mohammad H A: Vitamin D and oxidative stress in obese Iraqi sample with fibromyalgia syndrome. Int. J. Res. Dev. Pharm. L. Sci, 2015, 5(1), 1974-1980

58. Murooj G J, Eman S. S: Evaluation of fetuin A in obese and non- obese Iraqi women with fibromyalgia syndrome; Bulletin of Pharmaceutical and Medical Sciences (BOPAMS); 2017, 5 (1), 5001-5006

59. Andrew S, Steven E, Nicole $\mathrm{M}$ et al: Improvement in the Spatial Distribution of Pain, Somatic Symptoms, and Depression after a Weight Loss Intervention; The Journal of Pain, 2017; 18 (12): 1542-1550

60. Eduardo S, Aline A, Emmanuelle D et al: Serum levels of leptin and adiponectin and clinical parameters in women with fibromyalgia and overweight /obesity, Arch Endocrinol Metab. 2017;61/3;249-256

61. Koc,yig it and Okyay: The relationship between body mass index and pain, disease activity, depression and anxiety in women with fibromyalgia. PeerJ; 2018, 6:e4917;1-10 DOI 10.7717 / peerj.4917

62. Mehmet O Ç, Burcu D Ç, Hakan GS et al: The Association of Skinfold Anthropometric Measures, Body Composition and Disease Severity in Obese and Non-obese Fibromyalgia Patients: A Cross-sectional Study; Arch Rheumatol 2018;33(1):59-65.
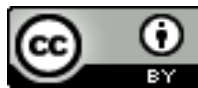

Baghdad Iraqi Journal Pharmaceutical Sciences by bijps is licensed under a Creative Commons Attribution 4.0 International License. Copyrights@ 2015 College of Pharmacy - University of Baghdad 